\title{
Chain Transfer to Solvent and Monomer in Early Transition Metal Catalyzed Olefin Polymerization: Mechanisms and Implications for Catalysis
}

\author{
Francesco Zaccaria ${ }^{1,2, *} \mathbb{D}$, Peter H. M. Budzelaar ${ }^{1}{ }^{\mathbb{D}}$, Cristiano Zuccaccia $^{2}$, Roberta Cipullo $^{1}{ }^{\mathbb{D}}$, \\ Alceo Macchioni ${ }^{2}{ }^{1}$, Vincenzo Busico ${ }^{1}$ and Christian Ehm ${ }^{1}{ }^{1}$ \\ 1 Dipartimento di Scienze Chimiche, Università degli Studi di Napoli Federico II, Via Cintia 21, \\ 80126 Napoli, Italy; p.budzelaar@unina.it (P.H.M.B.); roberta.cipullo@unina.it (R.C.); busico@unina.it (V.B.); \\ christian.ehm@unina.it (C.E.) \\ 2 Dipartimento di Chimica, Biologia e Biotecnologie and CIRCC, Università degli Studi di Perugia, Via Elce di \\ Sotto 8, 06123 Perugia, Italy; cristiano.zuccaccia@unipg.it (C.Z.); alceo.macchioni@unipg.it (A.M.) \\ * Correspondence: francesco.zaccaria@unipg.it
}

Citation: Zaccaria, F.; Budzelaar, P.H.M.; Zuccaccia, C.; Cipullo, R.; Macchioni, A.; Busico, V.; Ehm, C. Chain Transfer to Solvent and Monomer in Early Transition Metal Catalyzed Olefin Polymerization: Mechanisms and Implications for Catalysis. Catalysts 2021, 11, 215. https://doi.org/10.3390/catal11020215

Academic Editor: Jason C. Hicks

Received: 17 January 2021

Accepted: 2 February 2021

Published: 5 February 202

Publisher's Note: MDPI stays neutral with regard to jurisdictional claims in published maps and institutional affiliations.

Copyright: (c) 2021 by the authors. Licensee MDPI, Basel, Switzerland. This article is an open access article distributed under the terms and conditions of the Creative Commons Attribution (CC BY) license (https:/ / creativecommons.org/licenses/by/ $4.0 /)$.

\begin{abstract}
Even after several decades of intense research, mechanistic studies of olefin polymerization by early transition metal catalysts continue to reveal unexpected elementary reaction steps. In this mini-review, the recent discovery of two unprecedented chain termination processes is summarized: chain transfer to solvent (CTS) and chain transfer to monomer (CTM), leading to benzyl/tolyl and allyl type chain ends, respectively. Although similar transfer reactions are well-known in radical polymerization, only very recently they have been observed also in olefin insertion polymerization catalysis. In the latter context, these processes were first identified in Ti-catalyzed propene and ethene polymerization; more recently, CTS was also reported in Sc-catalyzed styrene polymerization. In the $\mathrm{Ti}$ case, these processes represent a unique combination of insertion polymerization, organic radical chemistry and reactivity of a $\mathrm{M}(\mathrm{IV}) / \mathrm{M}(\mathrm{III})$ redox couple. In the Sc case, CTS occurs via a $\sigma$-bond metathesis reactivity, and it is associated with a significant boost of catalytic activity and/or with tuning of polystyrene molecular weight and tacticity. The mechanistic studies that led to the understanding of these chain transfer reactions are summarized, highlighting their relevance in olefin polymerization catalysis and beyond.
\end{abstract}

Keywords: olefin polymerization; chain transfer; solvent activation; chain ends; homolysis; $\mathrm{Ti}(\mathrm{IV}) / \mathrm{Ti}(\mathrm{III})$ redox couple; $\sigma$-bond metathesis; low-molecular weight polystyrene

\section{Introduction}

Starting with the pioneering work by Cossee and Arlman in the 1960s [1,2], mechanistic studies of olefin polymerization catalysis have unveiled an intricate series of chain initiation, propagation and termination processes presiding over polymer formation. An in-depth understanding of these elementary steps is essential to rationalize the factors determining polymer microstructure, thereby opening avenues for rational tuning [3-5]. Molecular catalysts, typically based on group IV metal complexes, have played a crucial role in this respect. Initially, owing to their well-defined single center nature, they represented suitable molecular models for understanding the reactivity and selectivity of heterogeneous Ziegler-Natta systems [3-9]. More recently, the identification of structure/property correlations for molecular catalysts has drawn even more interest [10-15], due to the increasing importance of these systems for the industrial production of performance polymers [16,17].

When considering the polymerization mechanism, chain termination events are often regarded simply as side reactions to chain growth, even though they are actually very important in at least two aspects. First, controlling the reaction rate of chain termination over propagation allows polymer molecular weight tuning, determining important 
macroscopic properties like melt viscosity and glass transition temperature [18-20]. Second, the type of chain termination reaction determines the nature of chain ends (both 'heads' and 'tails', vide infra), which can affect macroscopic properties [21,22] and can be utilized to introduce functional end-groups. In the common case of ethene and simple $\alpha$-olefins like propene, functional end groups are typically limited to unsaturated $C=C$ bonds, which can be exploited for the production of olefin macro-monomers [23], or undergo chemical transformations to serve, for instance, as junctions in the synthesis of block copolymers [24,25].

Unsaturated chain ends are typically produced via $\beta-\mathrm{H}$ elimination (BHE) [5], $\beta$ $\mathrm{H}$ transfer to the monomer (BHTM) [26-28] and, more rarely, $\beta$-methyl elimination (BME) $[29,30]$, as depicted in Scheme 1 for the representative case of propene polymerization. Saturated chain ends, instead, usually derive from chain transfer to a main group metal cocatalyst (e.g., $\mathrm{Al}$ and $\mathrm{Zn}$ alkyls) [31,32] or reaction with molecular hydrogen (Scheme 1) [33,34]; additionally, they can derive from chain reinitiation via monomer insertion into metal-hydride and metal-alkyl species, generated after BHE/hydrogenolysis and BHTM/BME/chain transfer to the cocatalyst, respectively [5]. These chain termination mechanisms and their correlations with polymer microstructure have been extensively studied, and are discussed in depth in a number of reviews [3-5,8].
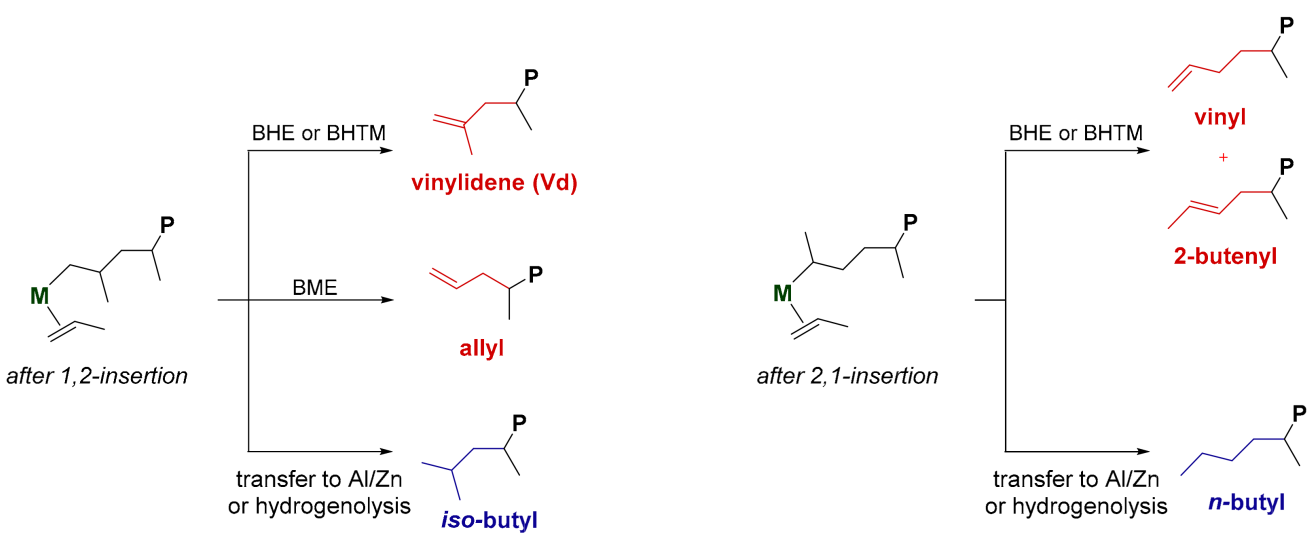

Scheme 1. Representative unsaturated (red) and saturated (blue) chain ends ('tails') obtained via the most common chain termination pathways in propene polymerization after 1,2- and 2,1- monomer insertion. $\mathrm{M}=$ transition metal, $\mathrm{P}$ = polymeryl.

In the last few years, however, our groups have identified an unusual termination route, namely homolytic chain transfer to solvent (CTS), which leads to atypical benzylterminated polymer chains when propene polymerization is carried out in toluene with certain Ti catalysts (Scheme 2A) [35-38]. Additionally, an analogous chain transfer to monomer (CTM) process was observed, generating allyl chain ends (Scheme 2B) similar to those obtained via BME (Scheme 1) [38]. Very recently, CTS via $\sigma$-bond metathesis has been observed also in styrene polymerization by the groups of Cui, Zhao and $\mathrm{Li}$, who detected tolyl chain ends in the polymer samples produced with Sc catalysts in toluene (Scheme 2C) [39,40]. It should be noted that similar CTS and CTM are rather common in radical polymerization [41-47], while they had never been observed before for transition metal catalyzed olefin insertion polymerization. 

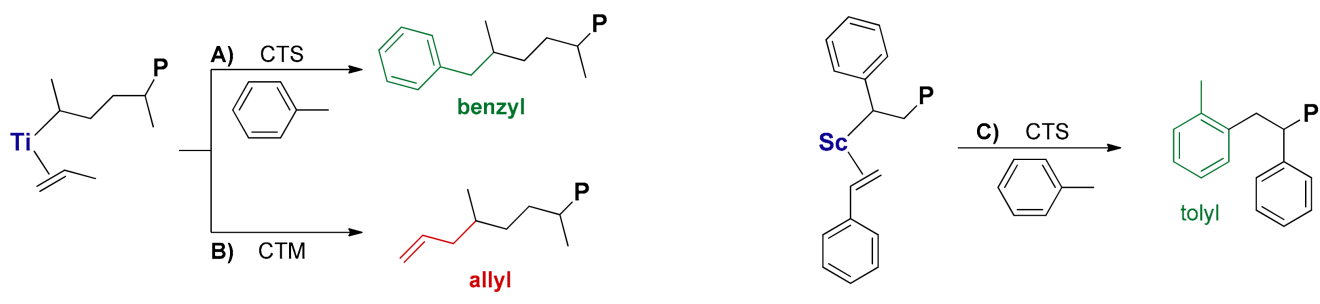

Scheme 2. Benzyl (A), allyl (B) and tolyl (C) chain ends deriving from chain transfer to solvent (CTS) or chain transfer to monomer (CTM). P = polymeryl.

In this account, we summarize the efforts to elucidate the mechanisms of these novel and unconventional chain termination reactions by combining polymerization experiments, spectroscopic studies and density functional theory (DFT) modeling. The results are put into perspective, highlighting connections with catalyst regioselectivity and thermal stability, and with other known but less common chain transfer processes. Furthermore, the potential relevance of this reactivity for the production of functionalized polymers, as well as for small molecule activation and synthesis of metal allyl complexes, is discussed.

\section{CTS and CTM in Ti-Catalyzed Propene Polymerization}

\subsection{First Observation and General Considerations}

The first observation of CTS [35] was reported in 2016 for Cp-phosphinimide Ti catalysts of the type introduced by Stephan and coworkers (1'-R and 1-R in Figure 1) [48]. When tested in propene polymerization at moderate $\left(80^{\circ} \mathrm{C}\right)$ to high $\left(110^{\circ} \mathrm{C}\right)$ polymerization temperature, these complexes produce polymer chains with sizable amounts of benzyl chain ends, which can be clearly identified by ${ }^{1} \mathrm{H}$ NMR polymer microstructural characterization (Figure 2). For the representative catalyst $\mathbf{1}^{\prime}$-Ph, between $12 \%$ and $32 \%$ of total chains are found to be benzylated, when polymerization is conducted at both low ( 0.3 bar) and moderately high (3.0 bar) monomer pressure.
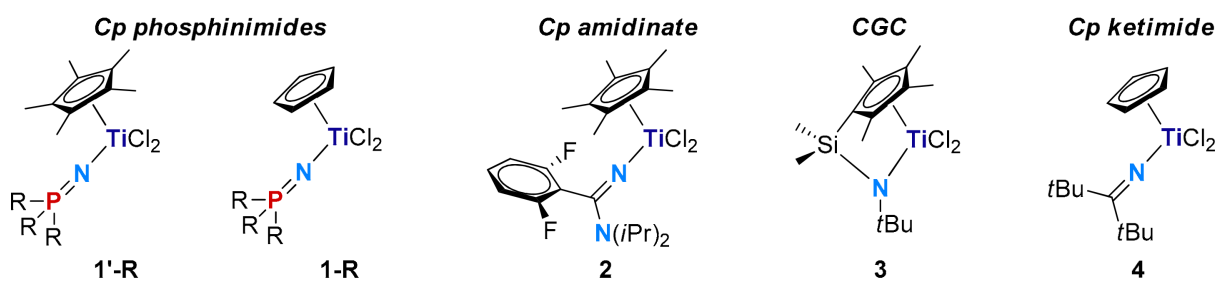

Figure 1. Representative Ti-based 'post-metallocenes'. $\mathrm{R}=$ alkyl or aryl.

Small amounts of benzyl chain ends are usually obtained when dibenzyl precatalysts are exploited, since the first monomer insertion occurs in the cationic monobenzylated active species. However, typical dichloride precursors were used in the aforementioned experiments; the only source of benzyl groups was the toluene solvent [35]. Solvent activation by highly reactive group IV cationic complexes is not unusual, but is generally associated with catalyst deactivation [49,50]. Here instead, C-H activation lead to solvent incorporation as polymer chain head, without killing the active species. Furthermore, up to seven benzyl terminated polymer chains are produced per metal center, assuming $100 \%$ active sites; this number increases significantly when considering a more reasonable fraction of $5-10 \%$ active Ti sites under polymerization conditions [51,52], clearly indicating that the generation of benzyl chain ends is a catalytic process. This reactivity appears to be facilitated by the use of MAO/BHT as cocatalyst $(\mathrm{MAO}=$ methylaluminoxane, $\mathrm{BHT}=2,6$ tert-butyl-4-methylphenol), although smaller amounts of benzyl chain ends are observed also with the binary system trityl borate/tri-iso-butylaluminum $[37,38]$. 


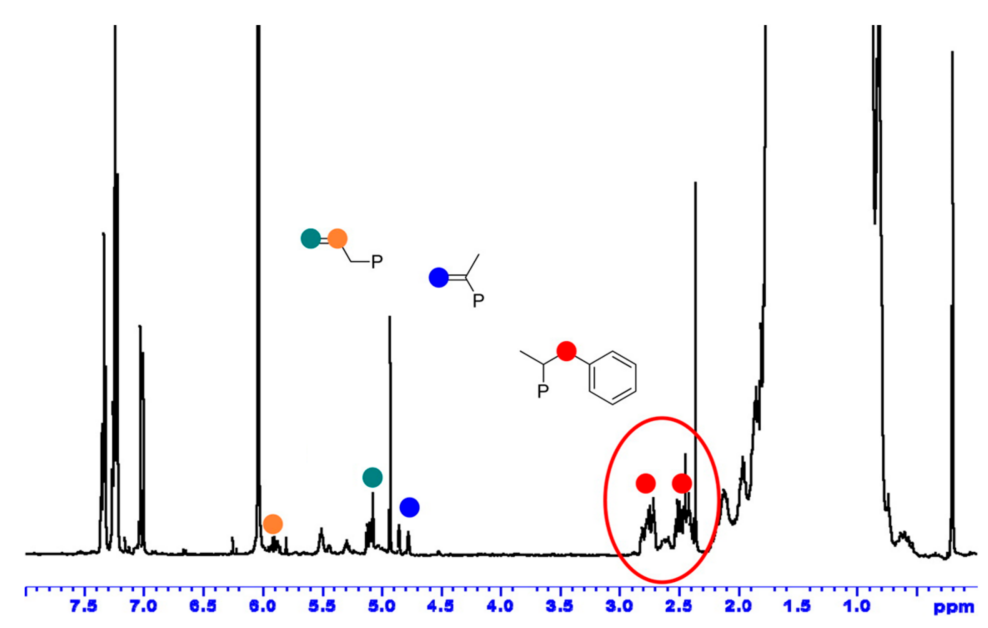

Figure 2. Representative ${ }^{1} \mathrm{H}$ NMR spectrum (tetrachloroethane- $d_{2}, 120^{\circ} \mathrm{C}$ ) of a polypropylene sample obtained with a Cp-phosphinimide Ti catalyst, showing the presence of benzyl chain ends (red) along with more typical olefinic terminations (blue, green, orange). Adapted with permission from Reference [35]. Copyright 2016 American Chemical Society.

Evidence for CTS was obtained also for other well-known and industrially relevant $\mathrm{Ti}$ catalysts, such as the Cp-amidinate (2) [53] and ansa-cyclopentadienylamido (3, Constrained Geometry Catalyst, CGC) [54] systems, while only 'classical' chain termination mechanisms were found to be operative, for instance, with Cp-ketimide complexes (4; Figure 1) [55]. In particular, catalyst 2 produces the highest amount of benzylated chain ends at $110{ }^{\circ} \mathrm{C}$ and 1 bar propene pressure reported so far $(50 \%)$; when the toluene concentration is decreased (toluene/aliphatic solvent mixture 1:9) this value drops to $15 \%$, while it increases to $~ 60 \%$ when toluene is replaced with the trimethylated analog mesitylene [37].

While benzyl groups represented a clear and rather unambiguous evidence for CTS, proving that CTM can be also operative in propene polymerization with these catalysts was less straightforward [37], since the resulting allyl chain ends could also be due to established mechanisms like BME (Scheme 1), as further discussed in the next section.

\subsection{Mechanistic Studies}

The large amount of saturated chain ends observable for polymers produced under CTS conditions, especially of $n$-butyl type (Table 1 ), indicates that termination mainly occurs after 2,1-propene insertion (Scheme 1) [35]. However, their formation via 'classical' mechanisms like chain transfer to cocatalyst and hydrogenolysis can be ruled out since the trimethylaluminum transfer agent present in $\mathrm{MAO}$ was completely trapped by addition of BHT [56-58], and no $\mathrm{H}_{2}$ was present in the reactor [35,37]. Therefore, formation of at least a large part of $n$-butyl chain ends can be traced to solvent activation. Consistent with this, it is known that insertion into Ti-sec-alkyl bonds (formed upon 2,1-propene insertion) is significantly slower than in Ti-n-alkyl bonds (derived from 1,2-insertion) [34,59-62], making side reactions like solvent activation more competitive with chain propagation for these so-called 'dormant' species.

The detailed mechanism of solvent activation was investigated, initially by means of DFT modeling [35,36]. A C-H activation via $\sigma$-bond metathesis, often observed with early transition metal alkyl complexes [63], could be excluded since calculated kinetic barriers were too high with respect to insertion ones, even for slowly inserting Ti-sec-alkyl species $\left(\Delta \Delta G^{\ddagger} \geq 13 \mathrm{kcal} / \mathrm{mol}\right.$ ) [35]. Moreover, preferential aromatic $\mathrm{C}-\mathrm{H}$ activation, and therefore tolyl rather than benzyl chain ends, would be expected for $\sigma$-bond metathesis reactivity [63]. 
Table 1. Summary of some microstructural parameters of polypropylene samples obtained with catalysts $1-3^{\text {a }}$.

\begin{tabular}{|c|c|c|c|c|c|c|c|c|}
\hline \multirow{2}{*}{ Entry } & \multirow{2}{*}{ Cat. } & \multirow{2}{*}{$M_{\mathrm{n}}{ }^{\mathrm{b}}$} & \multirow{2}{*}{$M_{\mathrm{w}}{ }^{\mathrm{b}}$} & \multirow{2}{*}{$\bigoplus$} & \multicolumn{2}{|c|}{$\%$ SAT ${ }^{c}$} & \multirow{2}{*}{$\%$ UNSAT $^{\mathrm{c}}$} & \multirow{2}{*}{$\% B n^{c}$} \\
\hline & & & & & Total & $n \mathrm{Bu}$ & & \\
\hline 1 & $1^{\prime}-\mathrm{Ph}$ & 3.3 & 6.4 & 2.0 & 160 & 79 & 19 & 21 \\
\hline 2 & $1^{\prime}-\mathrm{Cy}$ & 1.6 & 2.7 & 1.7 & 137 & 30 & 54 & 9 \\
\hline $3^{d}$ & $1^{\prime}-t \mathrm{Bu}$ & 1.4 & 1.6 & 1.2 & 127 & 23 & 77 & n.d. ${ }^{e}$ \\
\hline 4 & 1-Ph & 6.4 & 13 & 2.0 & 179 & 40 & 16 & 5 \\
\hline 5 & $1-\mathrm{Cy}$ & 4.1 & 7.8 & 1.9 & 168 & 58 & 19 & 14 \\
\hline 6 & $1-t \mathrm{Bu}$ & 2.3 & 3.9 & 1.8 & 165 & 69 & 26 & 9 \\
\hline 7 & 2 & 5.9 & 13 & 2.2 & 131 & 69 & 19 & 50 \\
\hline 8 & 3 & 4.1 & 7.4 & 1.8 & 148 & 49 & 48 & 4 \\
\hline
\end{tabular}

a Experimental conditions: Catalyst, $25 \mu \mathrm{mol}$; Toluene, $200 \mathrm{~mL}$; Activator, $\mathrm{MAO} / \mathrm{BHT} ; \mathrm{Al} / \mathrm{Ti}=400$; $p_{\text {propene }}=$ 1 bar; $T_{\mathrm{p}}=110{ }^{\circ} \mathrm{C}, t=15 \mathrm{~min} ;{ }^{\mathrm{b}}$ in $\mathrm{kDa} ;{ }^{\mathrm{c}} \mathrm{mol} \%$ of polymer chains with saturated (SAT), unsaturated (UNSAT) and benzyl (Bn) chain ends, determined by NMR spectroscopy (\%SAT values above $100 \%$ imply that a fraction of the polymer chains have an aliphatic head and tail); ${ }^{\mathrm{d}} T_{\mathrm{p}}=100{ }^{\circ} \mathrm{C} ;{ }^{\mathrm{e}}$ n.d. $=$ not detected. Data taken from Reference [37].

A radical pathway is more consistent with selective toluene activation at the benzylic position [64], and Ti-C bond homolysis is known to be competitive with olefin polymerization, especially at high temperature [65-68]. The quantitative computational modeling of this reaction required a dedicated benchmark study, which allowed to overcome the difficulties related to a) the 'transferability problem' [69] in the estimates of metal-carbon bond dissociation energies (BDEs) and $b$ ) the $1 \rightarrow 2$ particle nature of this reaction that poses a challenge for static DFT methodologies [36]. Analysis of BDEs for model species, such as $\mathrm{Cp}_{2} \mathrm{TiMe}_{2}$ and the cationic $\alpha$-agostic alkyl complexes $\left[\mathrm{Cp}_{2} \mathrm{Ti}-\mathrm{R}\right]^{+}$, revealed that homolysis of Ti-C bonds is thermodynamically accessible especially for $\left[\mathrm{Cp}_{2} \mathrm{Ti}-i \mathrm{Pr}\right]^{+}$(mimicking the active species after 2,1-propene insertion) rather than for $\left[\mathrm{Cp}_{2} \mathrm{Ti}-i \mathrm{Bu}\right]^{+}$(mimicking the active species after 1,2-propene insertion). This can be ascribed to the increased steric strain around the metal center that weakens the Ti-C bond in the former case, as well as the higher stability of secondary vs. primary alkyl radical products. Estimated BDEs are strongly affected by monomer coordination to the metal center (compare blue and red traces in Figure 3), as well as by the interaction with solvent [36] and counterion [36-38], eventually resulting in $\mathrm{Ti}-\mathrm{C}$ bond strengths comparable to (or even lower than) $\mathrm{O}-\mathrm{O}$ bonds of organic peroxides [70].

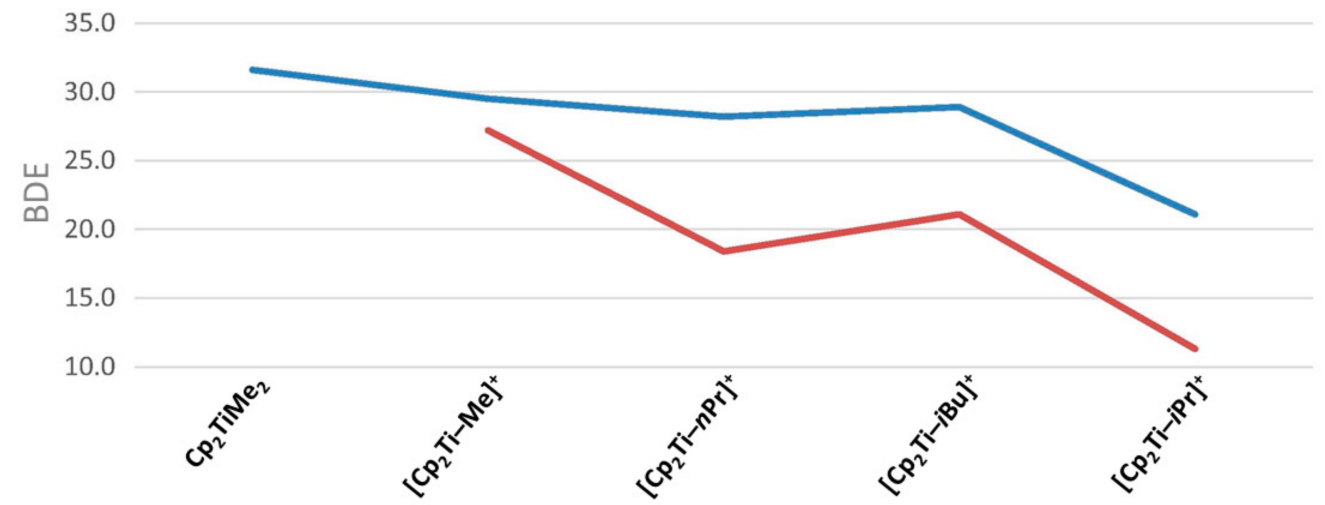

Figure 3. Density functional theory (DFT) calculated BDEs for $\mathrm{Cp}_{2} \mathrm{TiMe}_{2}$ and $[\mathrm{Cp} 2 \mathrm{Ti}-\mathrm{R}]^{+}$naked (blue trace) and olefin stabilized (red trace) cations at $298 \mathrm{~K}$. Adapted with permission from Reference [36].

Kinetic barriers for homolysis were also estimated, following the strategy proposed by Scott and Peters for Cr-alkyl species (i.e., assuming that the transition state is located 5-10 kcal/mol above the two separated radical fragments) [71], and compared with those for insertion. Already at $298 \mathrm{~K}$, the estimated $\Delta \Delta G^{\ddagger}$ (Hom.-Ins.) are slightly negative for 
the aforementioned bis-Cp species, and slightly positive for the 'post-metallocenes' 1-3 (Figure 1), in which the steric bulk around the metal center is reduced by the presence of the non-Cp ligands [36].

These computational results therefore confirm that the radical pathway for solvent activation is accessible under polymerization conditions and is favored by increased steric bulk around the metal center (e.g., bulky ancillary ligands and 2,1- vs. 1,2-last inserted monomer). Thus, the mechanism of CTS involves Ti-sec-polymeryl bond homolysis, benzylic $\mathrm{H}$-abstraction from toluene by the polymeryl radical, Ti(III)/benzyl radical recombination, and chain reinitiation by the newly formed Ti(IV)-Bn species (Scheme 3A).

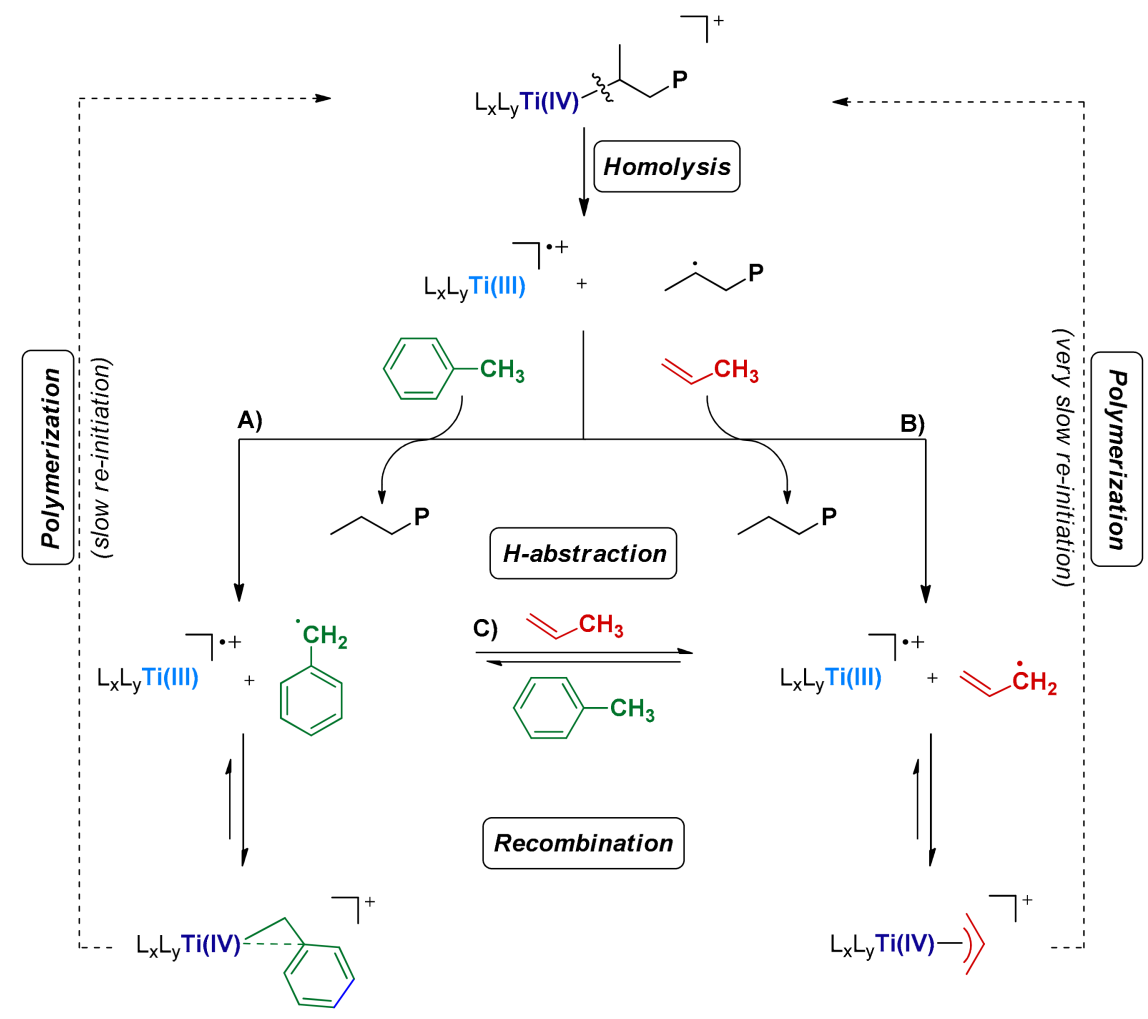

Scheme 3. Proposed mechanisms of CTS (A) and CTM (B), including possible crossover between them (C). Propene was selected as representative $\alpha$-olefin monomer. $\mathrm{L}=$ ancillary ligand, $\mathrm{P}=$ polymeryl. Adapted with permission from Reference [38].

Experimental evidence for this mechanistic proposal derived from the systematic screening of phosphinimide catalysts $\mathbf{1}-\mathbf{R}$ and $\mathbf{1}^{\prime}-\mathbf{R}(\mathrm{R}=$ phenyl, cyclohexyl and tert-butyl; Figure 1). These systems produce polymers with variable amounts of benzyl chain ends when tested in propene polymerization under the same reaction conditions (Table 1) [37]. The ratio between in-chain and terminal regioerrors (Int./Ter. RE) in the polypropylene samples can be used to estimate experimentally the relative probability of chain propagation and termination after 2,1-insertion. In line with the proposed homolytic mechanism for chain termination, trends in Int./Ter. RE reflect those in DFT estimated $\Delta \Delta G^{\ddagger}$ (Hom.-Ins.) and in the percentage of buried volume in the catalyst active pocket $\left(\% V_{\text {Bur }}\right.$, Figure 4$)$, which is a descriptor for the steric bulk around the metal center [72]. Trends in polymer $M_{\mathrm{n}}$ are also in line with this interpretation (Figure 4) [37]. 


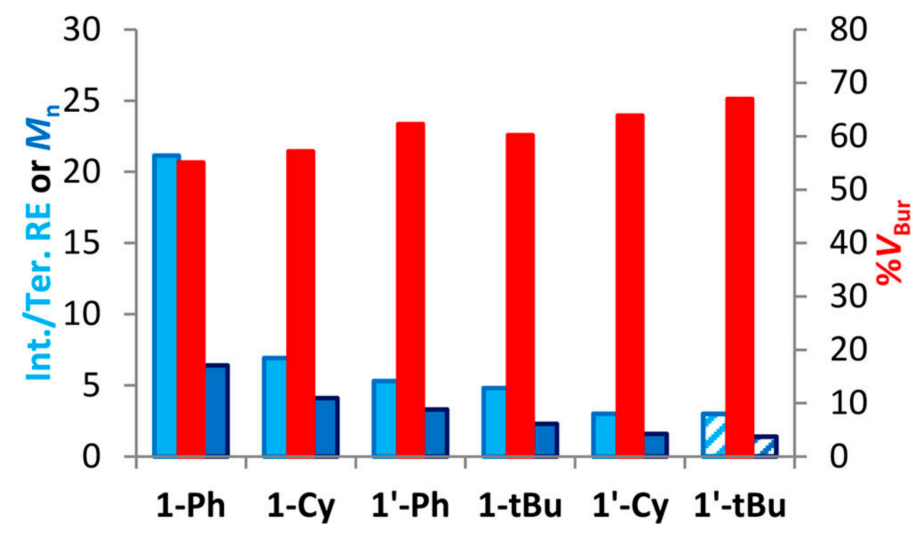

Figure 4. Graphical comparisons of trends in Int./Ter. RE (light blue) and $M_{\mathrm{n}}$ (dark blue; in kDa) with percentage of buried volume $\% V_{\text {Bur }}\left(\right.$ red). Experimental data for $\mathbf{1}^{\prime}-\boldsymbol{t} \mathbf{B u}$ are reported separately since they were obtained at slightly lower temperature $\left(100^{\circ} \mathrm{C}\right.$, see Reference [37] for details). Catalysts are ordered by decreasing $M_{\mathrm{n}}$. Reprinted with permission from Reference [37]. Copyright 2018 American Chemical Society.

Rationalizing factors determining the formation of benzyl terminated polymers was more complex, since it not only depends on the ease of Ti-polymeryl homolysis but also on the probability of $\mathrm{H}$ abstraction from toluene, $\mathrm{Ti}(\mathrm{III})$ /benzyl radical recombination, and chain reinitiation (Scheme 3A). Although no definitive conclusions can be drawn, combined experimental and computational data suggest that the main parameter determining solvent incorporation is $\Delta \Delta G^{\ddagger}$ (Hom.-Ins.) for the Ti(IV)-benzyl intermediate, that is, the probability that this species initiates chain growth rather than undergo further homolysis to go back to the $\mathrm{Ti}(\mathrm{III})$ and benzyl radicals (Scheme 3A) [37].

While screening the differently substituted phosphinimide catalysts, it emerged that the most sterically hindered $\mathbf{1}^{\prime}-\mathbf{t} \mathbf{B u}$ produces no benzyl terminated polymers, even though the large number of saturated end-groups indicated that homolysis is still a main chain termination event [37]. At the same time, this catalyst produces an unusually large amount of allyl chain ends. Given the similarity of BDEs for allylic $\mathrm{C}-\mathrm{H}$ bonds in propene $(\sim 88 \mathrm{kcal} / \mathrm{mol})$ and benzylic C-H bonds in toluene $(\sim 89 \mathrm{kcal} / \mathrm{mol})$ [73], allyl formation might also originate from chain transfer to monomer (CTM; Scheme 3B), via an analogous radical mechanism to that proposed for CTS (Scheme 3A) [37]. Crossovers are also possible between these two pathways (Scheme 3C).

Further supporting experimental evidence for this hypothesis derived from the direct NMR spectroscopic observation of the key Ti(IV)-benzyl and Ti(IV)-allyl intermediates under 1-hexene polymerization conditions with $\mathbf{1}^{\prime}$-t $\mathbf{B u}$ at $298 \mathrm{~K}$ (Figure 5) [38]. By taking advantage of the $\mathrm{P}$ atom in the ancillary ligand of the catalyst, it was possible to detect both intermediates using low amounts of monomer to retard chain propagation ( 10 eq.; Figure 5). Indications for their formation via a radical mechanism were obtained. It is worth mentioning that, at higher 1-hexene loadings ( 100 eq.; Figure 5), the Ti(IV)-benzyl complex is not observed anymore, since it is consumed by reaction with the monomer. Conversely, the Ti(IV)-allyl intermediate forms and accumulates even in the presence of excess 1-hexene, indicating that this species is 'dormant' under the experimental conditions used. This is the first time that dormant allyl-type intermediates have been detected for Ti catalysts; several examples for zirconocenes had been reported previously, albeit deriving from different reaction pathways (see Section 4.3 for further discussion) [74-78]. 

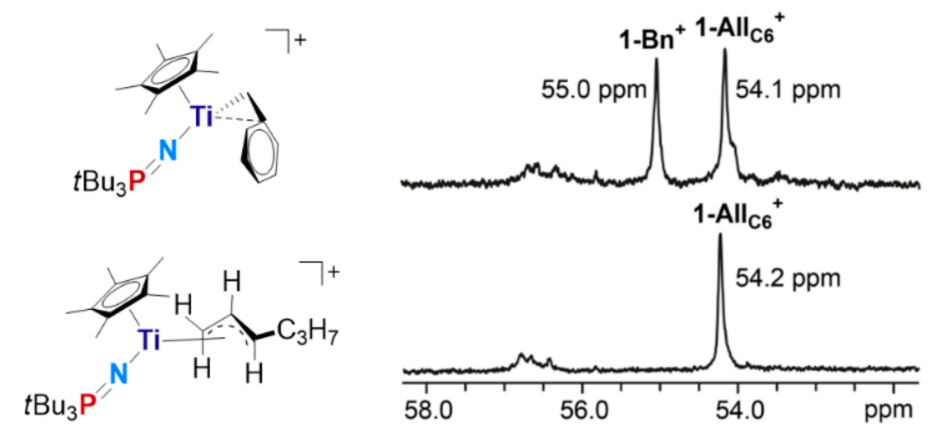

Figure 5. ${ }^{31} \mathrm{P}$ NMR (toluene- $d_{8}, 298 \mathrm{~K}$ ) spectra of the Ti(IV)-benzyl ('1-Bnn' ${ }^{+\prime}$ ) and Ti(IV)-allyl ('1$\mathbf{A l l}_{\mathbf{C} 6}{ }^{{ }^{\prime}}$ ) intermediates observed under polymerization conditions by reacting $\mathbf{1}^{\prime}$-tBu with $\sim 10$ (bottom) or >100 (top) eq. of 1-hexene. Reproduced with permission from Reference [38].

\section{CTS in Sc-Catalyzed Styrene Polymerization}

\subsection{Additive Triggered CTS}

In 2020, Cui and coworkers reported the first observation of CTS in styrene polymerization with Scandium catalysts bearing thiophene-fused cyclopentadienyl ligands (Figure 6) [39]. These systems are known to polymerize styrene with high activities and in a pseudoliving fashion [79]. In an attempt to copolymerize styrene with a functional comonomer like allyloxybenzene, however, the authors observed a rather expected decrease of catalyst productivity, but also an unexpected drop of polymer molecular weight to a few $\mathrm{kDa}$ [39]. Microstructural analysis, by NMR spectroscopy and MALDI-TOF mass spectrometry, revealed that no allyloxybenzene was incorporated in the polymer chains. Furthermore, they showed the formation of unsaturated chain ends, derived from BHE or BHTM, and of unprecedented ortho-tolyl chain ends, caused by solvent activation (Figure 6). Exploring concentration and temperature variations led to minor changes in terms of solvent incorporation, indicating that this CTS is highly competitive with chain propagation.

In contrast to propene polymerization, the preferential aromatic $\mathrm{C}-\mathrm{H}$ activation at toluene observed in this case suggests a $\sigma$-bond metathesis mechanism, typical of Sc-alkyl complexes [63]. Based on DFT modeling, the authors suggest that solvent activation is triggered by the coordination of allyloxybenzene to the active Sc center. This hampers styrene coordination to the metal, retarding chain propagation and favoring side reactions like $\mathrm{H}$-abstraction from weakly coordinated toluene solvent by the Sc-silylalkyl group (Scheme 4). The resulting Sc-tolyl species slowly initiates a tolyl capped chain growth.

It is worth mentioning that allyloxybenzene coordination appears to affect also stereoselectivity, leading to atactic rather than syndiotactic polymers [39]. The concomitant decrease of polymer molecular weight and tacticity is not necessarily undesirable: lowmolecular weight and atactic polystyrene find commercial applications, for instance, as precursor for brominated polystyrenes, serving as flame retardants and components of electrical devices [80]. This material is usually produced via hard-to-control anionic or radical polymerization, while the additive-triggered CTS process observed with Sc catalysts allows to obtain it via well-controlled coordination polymerization [39]. 


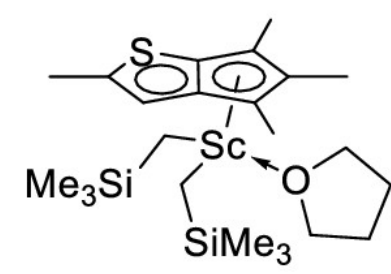

1

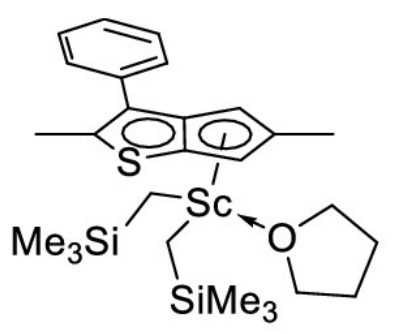

2

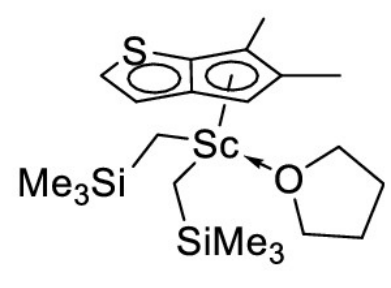

3
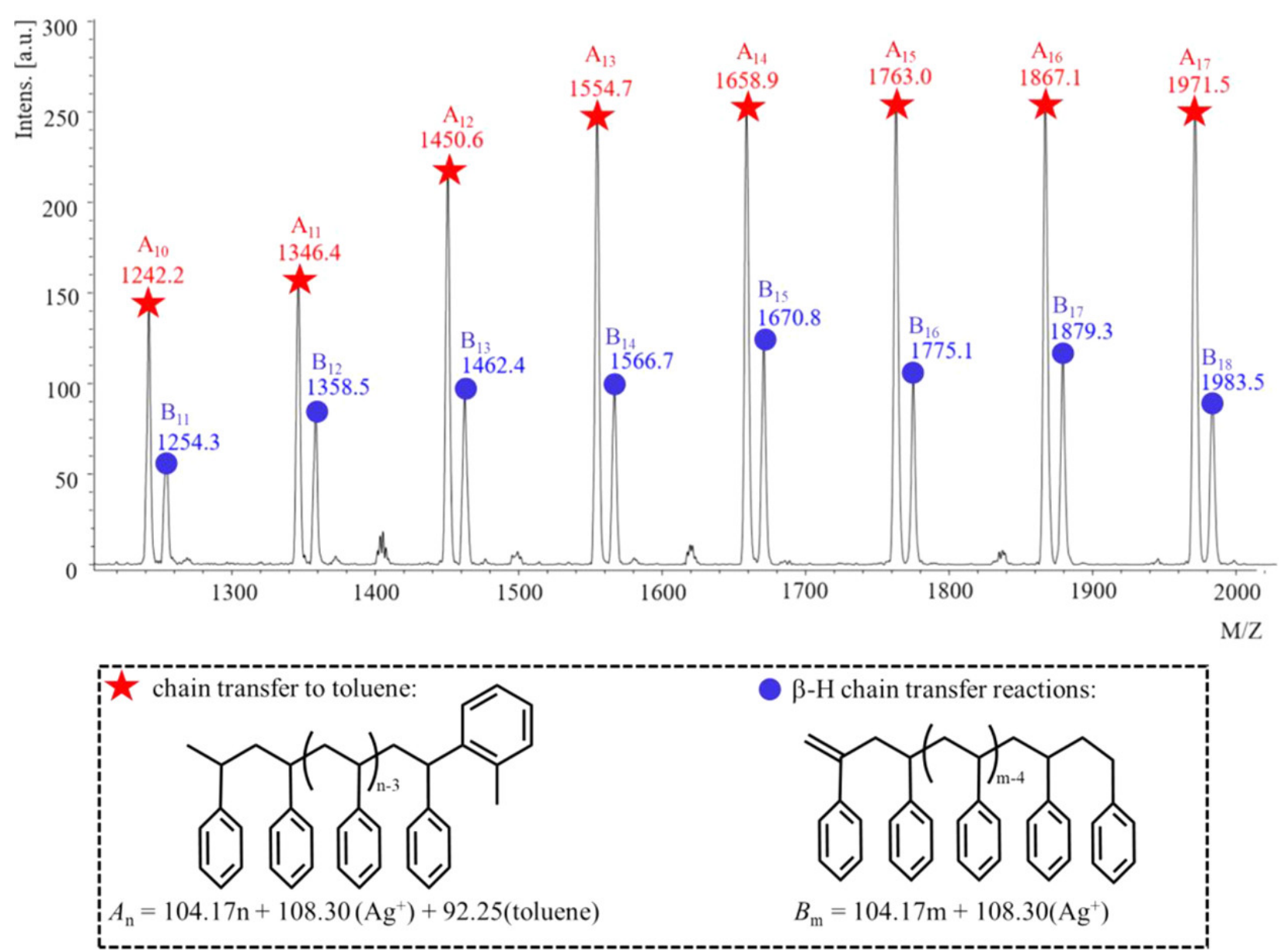

Figure 6. Sc precatalysts (top) and MALDI-TOF spectrum of the polystyrene samples (bottom) reported by Cui and coworkers. Adapted with permission from Reference [39]. Copyright 2020 American Chemical Society.

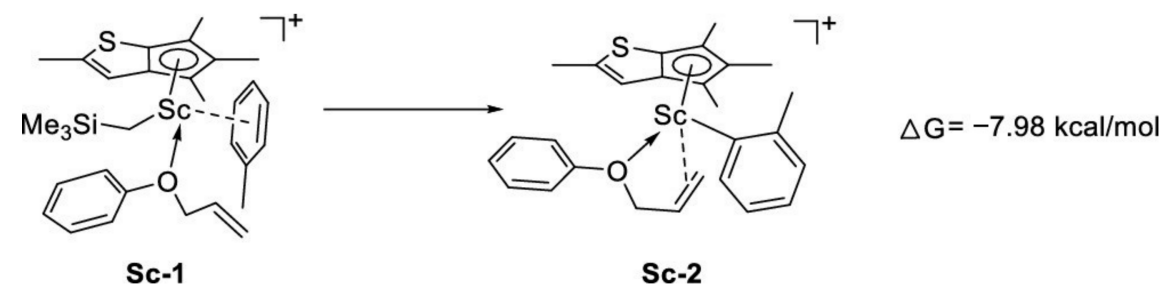

Scheme 4. Proposed mechanism for CTS in styrene polymerization triggered by allyloxybenzene. Reproduced with permission from Reference [39]. Copyright 2020 American Chemical Society.

\subsection{CTS by Highly Active $\beta$-Diketiminate Sc-Catalysts in Additive-Free Polymerization}

Cui and coworkers followed up on their initial report with another example of CTS in Sc-catalyzed styrene polymerization, this time in the absence of any additive [40]. In particular, the authors were interested in developing novel catalysts having ancillary 
ligands other than the established Cp-type fragments. Non-Cp complexes are often poorly active in styrene polymerization, including several examples based on $\beta$-diketiminate ligands [81]. However, upon installing fluorine substituents on the aryl rings of the $\beta$ diketiminate framework, Cui and coworkers observed a boost of productivity, reaching its maximum with the perfluorinated species (Figure 7) [40].<smiles></smiles><smiles>Fc1ccc([Al]=[Te])cc1</smiles>

Figure 7. Fluorine substituted $\beta$-diketiminate Sc catalysts reported by Cui and coworkers $(1 \leq \mathrm{n} \leq 5)[40]$.

This sharp increase of activity was ascribed to the enhanced electrophilicity of the metal center facilitating monomer coordination, and it is accompanied by a decrease of polymer molecular weight by two orders of magnitude with respect to the non-fluorinated catalyst. Also in this case, MALDI-TOF mass spectrometric characterization revealed the presence of ortho-tolyl chain ends in the polystyrene samples, followed by an unusual 1,2-inserted monomeric unit [40]. Similar end groups are obtained using xylene, while benzene and halogen substituted toluene derivatives are not incorporated.

The non-incorporation of benzene is particularly interesting, as it suggests that the $-\mathrm{CH}_{3}$ group of toluene plays a key role in solvent incorporation. With the help of DFT modeling, the mechanism for CTS was therefore proposed to involve a $\sigma$-bond metathesis $\mathrm{H}$-abstraction from toluene, favored by the interaction between the methyl group of the solvent and the fluorinated aryl ring of the catalysts (Scheme 5). This attractive interaction is also proposed to determine the high selectivity for ortho- over meta- and para- $\mathrm{H}$ activation. Similar to what was discussed in the previous section, CTS is therefore associated with the development of highly active Sc catalysts producing low-molecular weight polystyrenes [40].

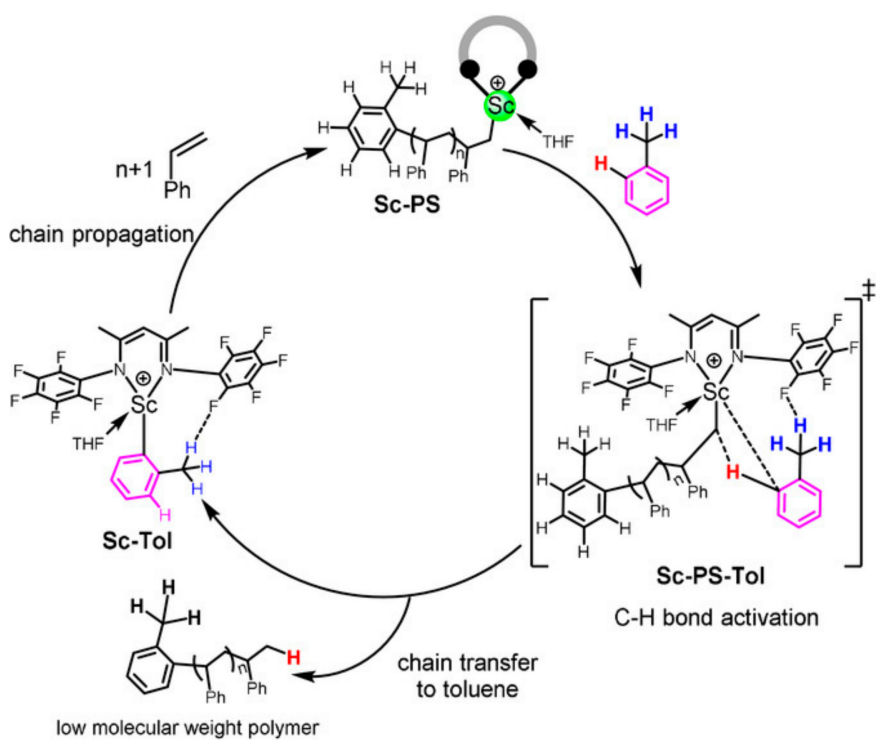

Scheme 5. Proposed mechanism for CTS in additive-free styrene polymerization by fluorinated $\beta$-diketiminate Sc catalysts. Reproduced with permission from Reference [40]. 


\section{Further Considerations on the Mechanisms of CTS and CTM, and Their Relevance in Catalysis}

\subsection{Connections with Catalyst Activity and Thermal Stability}

In molecular olefin polymerization catalysis, $\mathrm{Ti}(\mathrm{IV})-\mathrm{C}$ bond homolysis has long been considered an irreversible deactivation route, since the resulting Ti(III) molecular species are inactive in ethene and $\alpha$-olefin polymerization [65-67]. The elucidation of the CTS and CTM mechanisms is therefore particularly intriguing, since it unprecedentedly demonstrates that active $\mathrm{Ti}(\mathrm{IV})$ centers can be regenerated from inactive Ti(III) via recombination with an organic radical, potentially increasing catalyst mileage [37]. Furthermore, it highlights the role of 2,1-monomer insertion not only in affecting polymer microstructure, but also as a catalyst stability 'stress test' due to the weakness of the resulting Ti-sec-alkyl bonds [36].

This reactivity has not been observed with zirconium-based systems, since $\mathrm{Zr}(\mathrm{IV})-\mathrm{C}$ bonds are significantly stronger than Ti analogs. Nevertheless, generating $\mathrm{Zr}$ (III) species should be possible under certain reaction conditions [36,82], and it cannot be excluded that radical generated benzyl or allyl type chain ends will be reported for zirconium catalysts in the future.

Likewise, in the case of ethene polymerization, only relatively strong $M-n$-alkyl rather than M-sec-alkyl bonds are expected, making homolysis less competitive with chain propagation. Nevertheless, benzyl terminated polyethylene chains could be observed with the amidinate catalyst 2 when working at high temperature $\left(110^{\circ} \mathrm{C}\right)$ and moderate monomer pressure (1 bar) [37]. This indicates that CTS and CTM can be accessible also for Ti-n-alkyl intermediates formed in ethene homopolymerization, at least under harsh reaction conditions typical, for instance, of reactor hotspots.

Different considerations apply to CTS by Sc catalysts. The $\sigma$-bond metathesis reactivity does not involve oxidation state changes of the metal and formation of inactive species. In principle, effects on catalysts activity might still derive from the formation of 'dormant' Sc-tolyl species, but the high activity of $\beta$-diketiminate catalysts indicates that this is not the case at least for these systems.

\subsection{Functionalized Polymers and Switchable Polymerization Catalysts}

Besides mechanistic understanding, CTS might be of interest also with respect to applications. A first example could be the synthesis of chain end aryl functionalized polymers, which could be achieved by using substituted toluenes as solvents. This approach is hampered by the low tolerance of the active species towards heteroatoms, and by the need for ideally $100 \%$ functionalized chains. Although no successful examples have been reported yet [40], the Sc catalysts might be somewhat more promising in this respect: they provide high percentages of tolyl terminated polystyrenes, and examples of anisole-derived chain ends have been already reported by a reaction pathway similar to CTS [83]. The ability of these systems to selectively activate the aromatic $\mathrm{C}-\mathrm{H}$ bonds of toluene, not those of styrene, is another important aspect.

Furthermore, the reversible redox chemistry of the Ti(IV)/Ti(III) couple under CTS and CTM conditions provides a potential handle for designing switchable polymerization catalysts [84]. Indeed, controlling the oxidation state of the metal center might allow to simultaneously exploit the ability of Ti(IV) centers to catalyze olefin insertion polymerization, and that of the $\mathrm{Ti}(\mathrm{III})$ center to polymerize styrene $[85,86]$ and functionalized olefins [87]. It is also worth mentioning that the mechanism of CTS and CTM is reminiscent of that of organometallic-mediated radical polymerization (OMRP) [88,89], in which chain propagation occurs via a radical mechanism, and the redox chemistry of the metal center is only exploited to stabilize the radical intermediates ("persistent radical effect"). Examples of OMRP based on the Ti(IV)/Ti(III) redox couple have been reported for instance by the group of Asandei, who successfully followed this strategy to synthesize a variety of homo and copolymers with low polydispersities [90-92]. Although the combination of insertion polymerization and radical chemistry poses significant challenges, interesting results have been recently reported for late transition metal catalysts [93-97]. 


\subsection{Connections with Small Molecule Activation and the Synthesis of Allyl Complexes}

The mechanism of CTS and CTM is based on two known types of reactivity, namely $\sigma$-bond metathesis for Sc catalysts and M(IV)/M(III) redox chemistry for Ti systems. While the former reactivity is indeed well-established [63], the controlled exploitation of the redox chemistry of Ti complexes is still a challenging and relatively underdeveloped field [98]. The demystification of CTS and CTM is therefore of general interest for the organometallic chemistry of Ti complexes. In this respect, it should be noted that the mechanisms depicted in Scheme 3 resemble the one proposed by Piers and coworkers for $\mathrm{C}-\mathrm{X}$ activation of halobenzenes by the hydride complex of $\mathbf{1}^{\prime}-\mathbf{t B u}$ (Scheme 6) [99,100], indicating that the $\mathrm{Ti}(\mathrm{IV}) / \mathrm{Ti}(\mathrm{III})$ redox couple in phosphinimide complexes might be easily exploited also for small molecule activation.

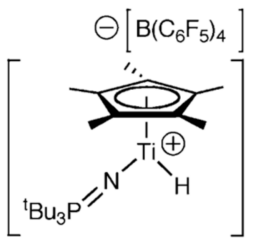

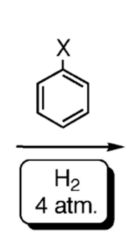

2X

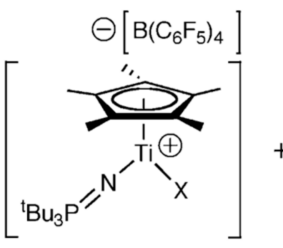

$\mathbf{X}-\mathrm{THF} \|+\mathrm{THF}$

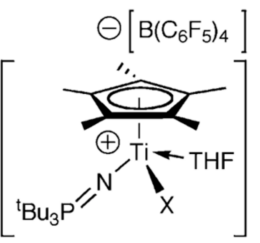

2X-THF

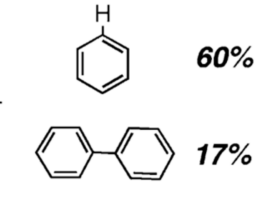

$17 \%$

Scheme 6. Homolytic C-X activation of chloro- and bromobenzene by $\mathbf{1}^{\prime}-\mathbf{t} \mathbf{B u}$ as reported by Piers and coworkers. Reproduced with permission from Reference [100]. Copyright 2006 American Chemical Society.

Furthermore, the mechanistic studies on these novel chain termination processes revealed easy routes to access Ti(IV)-allyl complexes. These species are of interest in organic synthesis, but they are generally difficult to isolate [101-104]. By employing higher $\alpha$-olefins, we have shown that allyl complexes can be easily accessible with phosphinimide catalysts, not only under polymerization conditions using 1-hexene, but also via straightforward routes using non-inserting olefins like 2-methyl-1-heptene (Scheme 7) [38].

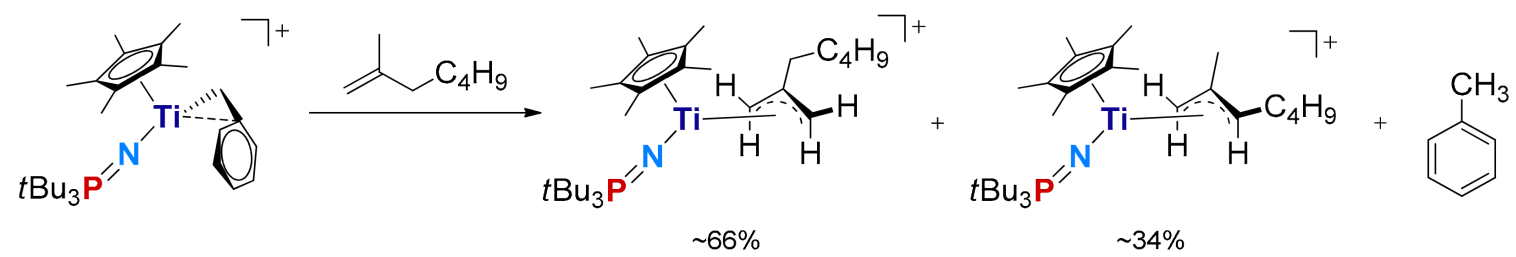

Scheme 7. Synthesis of well-defined Ti(IV)-allyl complexes by reaction of $\mathbf{1}^{\prime}$ - $\mathbf{t} \mathbf{B u}$ with 2-methyl-1-heptene [38].

Formation of allyl complexes by $\mathrm{H}$-abstraction from a non-inserting olefin has been observed also for zirconocenes, in that case through $\sigma$-bond metathesis [105-107]. It should be noted also that dormant polymeryl carrying allyl-type complexes are often formed in situ under polymerization conditions with zirconocene catalysts; in this case, the allyl complex does not derive from monomer activation, but rather by BHE from a Zr-polymeryl species and allylic $\mathrm{C}-\mathrm{H}$ activation by the resulting hydride complex [74-78]. This reactivity is therefore different from that of CTM, and does not lead to allyl-type chain ends [3-5,8]. 


\section{Conclusions}

The recent discovery of CTS and CTM exemplifies the intriguing complexity of the olefin polymerization mechanism, which still needs to be fully unveiled. These two novel chain transfer processes were first identified in Ti-catalyzed propene polymerization by the presence of benzyl and allyl-type chain ends in the polymer samples. Their detailed mechanistic investigation demonstrated an unexpected combination of insertion polymerization and radical chemistry. Furthermore, it highlighted the importance of 2,1-monomer insertion for catalyst thermal stability, the existence of reactivation routes for Ti(III) species, and the formation of dormant Ti(IV)-allyl type complexes under polymerization conditions. This reactivity was observed with several industrially relevant 'post-metallocenes', and also in ethene homopolymerization albeit under harsher reaction conditions. Clearly, CTS is accessible with toluene, often used in academic laboratories, and with analogous solvents having $\mathrm{C}-\mathrm{H}$ bonds of the right strength; conversely, it is less likely in the saturated hydrocarbons typically preferred by industry, although CTM should still be operative in this case.

Recent reports on tolyl terminated polystyrenes demonstrate that CTS can occur also in Sc-catalyzed styrene polymerization, in this case via a 'classical' $\sigma$-bond metathesis mechanism. The first observation with cyclopenta[b]thienyl Sc catalysts was triggered by the presence of allyloxybenzene, while the second occurred in additive-free styrene polymerization with highly active fluorinated $\beta$-diketiminate complexes. In both cases, CTS offers viable and unusual catalytic routes for the production of low-molecular weight polystyrenes via coordination polymerization.

The identification of CTS and CTM is relevant not only in terms of mechanistic understanding, but also for some potential applications like the synthesis of chain end functionalized macromolecules and of block copolymers via switchable polymerization. While these approaches represent significant challenges, it might be expected that some advances will be achieved in the foreseeable future, also in light of recent literature reports on combined insertion and radical polymerization with late transition metal catalysts [93-97].

Funding: Part of this work has been financially supported by the University of Perugia and MIUR (AMIS, “Dipartimenti di Eccellenza 2018-2022” program).

Acknowledgments: F.Z. thanks INSTM and CIRCC for a post-doctoral grant.

Conflicts of Interest: The authors declare no conflict of interest.

\section{References}

1. Cossee, P. On the reaction mechanism of the ethylene polymerization with heterogeneous ziegler-natta catalysts. Tetrahedron Lett. 1960, 1, 12-16. [CrossRef]

2. Arlman, E.J.; Cossee, P. Ziegler-Natta catalysis III. Stereospecific polymerization of propene with the catalyst system $\mathrm{TiCl}_{3} \mathrm{AlEt}_{3}$. J. Catal. 1964, 3, 99-104. [CrossRef]

3. Busico, V.; Cipullo, R. Microstructure of polypropylene. Prog. Polym. Sci. 2001, 26, 443-533. [CrossRef]

4. Resconi, L.; Cavallo, L.; Fait, A.; Piemontesi, F. Selectivity in Propene Polymerization with Metallocene Catalysts. Chem. Rev. 2000, 100, 1253-1346. [CrossRef]

5. Resconi, L.; Camurati, I.; Sudmeijer, O. Chain transfer reactions in propylene polymerization with zirconocene catalysts. Top. Catal. 1999, 7, 145-163. [CrossRef]

6. Bochmann, M. Cationic Group 4 metallocene complexes and their role in polymerisation catalysis: The chemistry of well defined Ziegler catalysts. J. Chem. Soc. Dalton Trans. 1996, 255-270. [CrossRef]

7. Zaccaria, F.; Sian, L.; Zuccaccia, C.; Macchioni, A. Ion pairing in transition metal catalyzed olefin polymerization. In Advances in Organometallic Chemistry; Perez, P.J., Ed.; Academic Press: Cambridge, MA, USA, 2020; Volume 73, pp. 1-78.

8. Brintzinger, H.H.; Fischer, D.; Mülhaupt, R.; Rieger, B.; Waymouth, R.M. Stereospecific Olefin Polymerization with Chiral Metallocene Catalysts. Angew. Chem. Int. Ed. Engl. 1995, 34, 1143-1170. [CrossRef]

9. Busico, V.; Cipullo, R.; Pellecchia, R.; Ronca, S.; Roviello, G.; Talarico, G. Design of stereoselective Ziegler-Natta propene polymerization catalysts. Proc. Natl. Acad. Sci. USA 2006, 103, 15321-15326. [CrossRef] [PubMed]

10. Ehm, C.; Vittoria, A.; Goryunov, G.P.; Kulyabin, P.S.; Budzelaar, P.H.M.; Voskoboynikov, A.Z.; Busico, V.; Uborsky, D.V.; Cipullo, R. Connection of Stereoselectivity, Regioselectivity, and Molecular Weight Capability in rac-R'2Si(2-Me-4-R-indenyl)2ZrCl2 Type Catalysts. Macromolecules 2018, 51, 8073-8083. [CrossRef] 
11. Uborsky, D.V.; Mladentsev, D.Y.; Guzeev, B.A.; Borisov, I.S.; Vittoria, A.; Ehm, C.; Cipullo, R.; Hendriksen, C.; Friederichs, N.; Busico, V.; et al. C1-Symmetric Si-bridged (2-indenyl)(1-indenyl) ansa-metallocenes as efficient ethene/1-hexene copolymerization catalysts. Dalton Trans. 2020, 49, 3015-3025. [CrossRef] [PubMed]

12. Ehm, C.; Vittoria, A.; Goryunov, P.G.; Izmer, V.V.; Kononovich, S.D.; Samsonov, V.O.; Di Girolamo, R.; Budzelaar, H.M.P.; Voskoboynikov, Z.A.; Busico, V.; et al. An Integrated High Throughput Experimentation/Predictive QSAR Modeling Approach to ansa-Zirconocene Catalysts for Isotactic Polypropylene. Polymers 2020, 12, 1005. [CrossRef]

13. Ehm, C.; Vittoria, A.; Goryunov, G.P.; Izmer, V.V.; Kononovich, D.S.; Samsonov, O.V.; Budzelaar, P.H.M.; Voskoboynikov, A.Z.; Busico, V.; Uborsky, D.V.; et al. On the limits of tuning comonomer affinity of 'Spaleck-type' ansa-zirconocenes in ethene/1hexene copolymerization: A high-throughput experimentation/QSAR approach. Dalton Trans. 2020, 49, 10162-10172. [CrossRef] [PubMed]

14. Möhring, P.C.; Coville, N.J. Group 4 metallocene polymerisation catalysts: Quantification of ring substituent steric effects. Coord. Chem. Rev. 2006, 250, 18-35. [CrossRef]

15. Cruz, V.L.; Martinez, S.; Ramos, J.; Martinez-Salazar, J. 3D-QSAR as a Tool for Understanding and Improving Single-Site Polymerization Catalysts. A Review. Organometallics 2014, 33, 2944-2959. [CrossRef]

16. Baier, M.C.; Zuideveld, M.A.; Mecking, S. Post-Metallocenes in the Industrial Production of Polyolefins. Angew. Chem. Int. Ed. 2014, 53, 9722-9744. [CrossRef]

17. Klosin, J.; Fontaine, P.P.; Figueroa, R. Development of Group IV Molecular Catalysts for High Temperature Ethylene- $\alpha$-Olefin Copolymerization Reactions. Acc. Chem. Res. 2015, 48, 2004-2016. [CrossRef] [PubMed]

18. Fox, T.G.; Flory, P.J. Second-Order Transition Temperatures and Related Properties of Polystyrene. I. Influence of Molecular Weight. J. Appl. Phys. 1950, 21, 581-591. [CrossRef]

19. Hintermeyer, J.; Herrmann, A.; Kahlau, R.; Goiceanu, C.; Rössler, E.A. Molecular Weight Dependence of Glassy Dynamics in Linear Polymers Revisited. Macromolecules 2008, 41, 9335-9344. [CrossRef]

20. de Gennes, P.G. Scaling Concepts in Polymer Physics; Cornell University Press: Ithaca, NY, USA, 1981. [CrossRef]

21. Rudin, A.; Burgin, D. Effects of molecular weight and chain ends on glass transition of polystyrene. Polymer 1975, 16, 291-297. [CrossRef]

22. Tsui, O.K.C.; Zhang, H.F. Effects of Chain Ends and Chain Entanglement on the Glass Transition Temperature of Polymer Thin Films. Macromolecules 2001, 34, 9139-9142. [CrossRef]

23. Stürzel, M.; Mihan, S.; Mülhaupt, R. From Multisite Polymerization Catalysis to Sustainable Materials and All-Polyolefin Composites. Chem. Rev. 2016, 116, 1398-1433. [CrossRef] [PubMed]

24. Goring, P.D.; Morton, C.; Scott, P. End-functional polyolefins for block copolymer synthesis. Dalton Trans. 2019, 48, 3521-3530. [CrossRef]

25. Kim, J.; Jung, H.Y.; Park, M.J. End-Group Chemistry and Junction Chemistry in Polymer Science: Past, Present, and Future. Macromolecules 2020. [CrossRef]

26. Talarico, G.; Budzelaar, P.H.M. Variability of Chain Transfer to Monomer Step in Olefin Polymerization. Organometallics 2008, 27, 4098-4107. [CrossRef]

27. Stehling, U.; Diebold, J.; Kirsten, R.; Roell, W.; Brintzinger, H.H.; Juengling, S.; Muelhaupt, R.; Langhauser, F. ansa-Zirconocene Polymerization Catalysts with Anelated Ring Ligands-Effects on Catalytic Activity and Polymer Chain Length. Organometallics 1994, 13, 964-970. [CrossRef]

28. Margl, P.; Deng, L.; Ziegler, T. A Unified View of Ethylene Polymerization by d0 and d0fn Transition Metals. 3. Termination of the Growing Polymer Chain. J. Am. Chem. Soc. 1999, 121, 154-162. [CrossRef]

29. Jeske, G.; Schock, L.E.; Swepston, P.N.; Schumann, H.; Marks, T.J. Highly reactive organolanthanides. Synthesis, chemistry, and structures of $4 \mathrm{f}$ hydrocarbyls and hydrides with chelating bis(polymethylcyclopentadienyl) ligands. J. Am. Chem. Soc. 1985, 107, 8103-8110. [CrossRef]

30. Bunel, E.; Burger, B.J.; Bercaw, J.E. Carbon-carbon bond activation via. beta.-alkyl elimination. Reversible branching of 1,4pentadienes catalyzed by scandocene hydride derivatives. J. Am. Chem. Soc. 1988, 110, 976-978. [CrossRef]

31. Chien, J.C.W.; Wang, B.-P. Metallocene-methylaluminoxane catalysts for olefin polymerization. I. Trimethylaluminum as coactivator. J. Polym. Sci. Part A Polym. Chem. 1988, 26, 3089-3102. [CrossRef]

32. Resconi, L.; Bossi, S.; Abis, L. Study on the role of methylalumoxane in homogeneous olefin polymerization. Macromolecules 1990, 23, 4489-4491. [CrossRef]

33. Chadwick, J.C.; Van Kessel, G.M.M.; Sudmeijer, O. Regio- and stereospecificity in propene polymerization with MgCl2-supported Ziegler-Natta catalysts: Effects of hydrogen and the external donor. Macromol. Chem. Phys. 1995, 196, 1431-1437. [CrossRef]

34. Busico, V.; Cipullo, R.; Chadwick, J.C.; Modder, J.F.; Sudmeijer, O. Effects of Regiochemical and Stereochemical Errors on the Course of Isotactic Propene Polyinsertion Promoted by Homogeneous Ziegler-Natta Catalysts. Macromolecules 1994, 27, 7538-7543. [CrossRef]

35. Ehm, C.; Cipullo, R.; Passaro, M.; Zaccaria, F.; Budzelaar, P.H.M.; Busico, V. Chain Transfer to Solvent in Propene Polymerization with Ti Cp-phosphinimide Catalysts: Evidence for Chain Termination via Ti-C Bond Homolysis. ACS Catal. 2016, 6, 7989-7993. [CrossRef]

36. Ehm, C.; Budzelaar, P.H.M.; Busico, V. Metal-carbon bond strengths under polymerization conditions: 2,1-insertion as a catalyst stress test. J. Catal. 2017, 351, 146-152. [CrossRef] 
37. Zaccaria, F.; Ehm, C.; Budzelaar, P.H.M.; Busico, V.; Cipullo, R. Catalyst Mileage in Olefin Polymerization: The Peculiar Role of Toluene. Organometallics 2018, 37, 2872-2879. [CrossRef]

38. Zaccaria, F.; Zuccaccia, C.; Cipullo, R.; Budzelaar, P.H.M.; Macchioni, A.; Busico, V.; Ehm, C. Toluene and $\alpha$-Olefins as Radical Scavengers: Direct NMR Evidence for Homolytic Chain Transfer Mechanism Leading to Benzyl and "Dormant" Titanium Allyl Complexes. Organometallics 2018, 37, 4189-4194. [CrossRef]

39. Liu, Z.; Yao, C.; Wu, C.; Zhao, Z.; Cui, D. Additive-Triggered Chain Transfer to a Solvent in Coordination Polymerization. Macromolecules 2020, 53, 1205-1211. [CrossRef]

40. Lin, F.; Liu, Z.; Wang, M.; Liu, B.; Li, S.; Cui, D. Chain Transfer to Toluene in Styrene Coordination Polymerization. Angew. Chem. Int. Ed. 2020, 59, 4324-4328. [CrossRef]

41. Magee, C.; Sugihara, Y.; Zetterlund, P.B.; Aldabbagh, F. Chain transfer to solvent in the radical polymerization of structurally diverse acrylamide monomers using straight-chain and branched alcohols as solvents. Polym. Chem. 2014, 5, $2259-2265$. [CrossRef]

42. Zetterlund, P.B.; Saka, Y.; McHale, R.; Nakamura, T.; Aldabbagh, F.; Okubo, M. Nitroxide-mediated radical polymerization of styrene: Experimental evidence of chain transfer to monomer. Polymer 2006, 47, 7900-7908. [CrossRef]

43. Peck, A.N.F.; Hutchinson, R.A. Secondary Reactions in the High-Temperature Free Radical Polymerization of Butyl Acrylate. Macromolecules 2004, 37, 5944-5951. [CrossRef]

44. Moghadam, N.; Srinivasan, S.; Grady, M.C.; Rappe, A.M.; Soroush, M. Theoretical Study of Chain Transfer to Solvent Reactions of Alkyl Acrylates. J. Phys. Chem. A 2014, 118, 5474-5487. [CrossRef]

45. Lessard, B.; Tervo, C.; Marić, M. High-Molecular-Weight Poly(tert-butyl acrylate) by Nitroxide-Mediated Polymerization: Effect of Chain Transfer to Solvent. Macromol. React. Eng. 2009, 3, 245-256. [CrossRef]

46. Tan, S.; Li, J.; Zhang, Z. Study of Chain Transfer Reaction to Solvents in the Initiation Stage of Atom Transfer Radical Polymerization. Macromolecules 2011, 44, 7911-7916. [CrossRef]

47. Kukulj, D.; Davis, T.P. Mechanism of catalytic chain transfer in the free-radical polymerisation of methyl methacrylate and styrene. Macromol. Chem. Phys. 1998, 199, 1697-1708. [CrossRef]

48. Stephan, D.W.; Stewart, J.C.; Guérin, F.; Spence, R.E.V.H.; Xu, W.; Harrison, D.G. Phosphinimides as a Steric Equivalent to Cyclopentadienyl: An Approach to Ethylene Polymerization Catalyst Design. Organometallics 1999, 18, 1116-1118. [CrossRef]

49. Rios, I.G.; Novarino, E.; van der Veer, S.; Hessen, B.; Bouwkamp, M.W. Amine Catalyzed Solvent C-H Bond Activation as Deactivation Route for Cationic Decamethylzirconocene Olefin Polymerization Catalysts. J. Am. Chem. Soc. 2009, 131, 16658-16659. [CrossRef]

50. Wu, F.; Dash, A.K.; Jordan, R.F. Structures and Reactivity of $\mathrm{Zr}(\mathrm{IV})$ Chlorobenzene Complexes. J. Am. Chem. Soc. 2004, 126, 15360-15361. [CrossRef]

51. Ghiotto, F.; Pateraki, C.; Severn, J.R.; Friederichs, N.; Bochmann, M. Rapid evaluation of catalysts and MAO activators by kinetics: What controls polymer molecular weight and activity in metallocene/MAO catalysts? Dalton Trans. 2013, 42, 9040-9048. [CrossRef]

52. Desert, X.; Carpentier, J.-F.; Kirillov, E. Quantification of active sites in single-site group 4 metal olefin polymerization catalysis. Coord. Chem. Rev. 2019, 386, 50-68. [CrossRef]

53. van Doremaele, G.; van Duin, M.; Valla, M.; Berthoud, A. On the Development of Titanium k1-Amidinate Complexes, Commercialized as Keltan ACE ${ }^{\mathrm{TM}}$ Technology, Enabling the Production of an Unprecedented Large Variety of EPDM Polymer Structures. J. Polym. Sci. Part A Polym. Chem. 2017, 55, 2877-2891. [CrossRef]

54. McKnight, A.L.; Waymouth, R.M. Group 4 ansa-Cyclopentadienyl-Amido Catalysts for Olefin Polymerization. Chem. Rev. 1998, 98, 2587-2598. [CrossRef]

55. Ferreira, M.J.; Martins, A.M. Group 4 ketimide complexes: Synthesis, reactivity and catalytic applications. Coord. Chem. Rev. 2006, 250, 118-132. [CrossRef]

56. Busico, V.; Cipullo, R.; Cutillo, F.; Friederichs, N.; Ronca, S.; Wang, B. Improving the Performance of Methylalumoxane: A Facile and Efficient Method to Trap "Free" Trimethylaluminum. J. Am. Chem. Soc. 2003, 125, 12402-12403. [CrossRef] [PubMed]

57. Zaccaria, F.; Zuccaccia, C.; Cipullo, R.; Budzelaar, P.H.M.; Macchioni, A.; Busico, V.; Ehm, C. BHT-Modified MAO: Cage Size Estimation, Chemical Counting of Strongly Acidic Al Sites, and Activation of a Ti-Phosphinimide Precatalyst. ACS Catal. 2019, 9 , 2996-3010. [CrossRef]

58. Zaccaria, F.; Zuccaccia, C.; Cipullo, R.; Budzelaar, P.H.M.; Macchioni, A.; Busico, V.; Ehm, C. On the nature of the Lewis acidic sites in 'TMA-free' phenol-modified Methylaluminoxane. Eur. J. Inorg. Chem. 2020, 2020, 1088-1095. [CrossRef]

59. Busico, V.; Cipullo, R.; Romanelli, V.; Ronca, S.; Togrou, M. Reactivity of Secondary Metal-Alkyls in Catalytic Propene Polymerization: How Dormant Are "Dormant Chains"? J. Am. Chem. Soc. 2005, 127, 1608-1609. [CrossRef]

60. Landis, C.R.; Sillars, D.R.; Batterton, J.M. Reactivity of Secondary Metallocene Alkyls and the Question of Dormant Sites in Catalytic Alkene Polymerization. J. Am. Chem. Soc. 2004, 126, 8890-8891. [CrossRef] [PubMed]

61. Flisak, Z.; Ziegler, T. "Dormant" secondary metal-alkyl complexes are not omnipresent. Proc. Natl. Acad. Sci. USA 2006, 103, 15338-15342. [CrossRef] [PubMed]

62. Song, F.; Cannon, R.D.; Bochmann, M. Zirconocene-Catalyzed Propene Polymerization: A Quenched-Flow Kinetic Study. J. Am. Chem. Soc. 2003, 125, 7641-7653. [CrossRef] [PubMed] 
63. Thompson, M.E.; Baxter, S.M.; Bulls, A.R.; Burger, B.J.; Nolan, M.C.; Santarsiero, B.D.; Schaefer, W.P.; Bercaw, J.E. $\sigma$-Bond metathesis for carbon-hydrogen bonds of hydrocarbons and Sc-R $(\mathrm{R}=\mathrm{H}$, alkyl, aryl) bonds of permethylscandocene derivatives. Evidence for noninvolvement of the. pi. system in electrophilic activation of aromatic and vinylic C-H bonds. J. Am. Chem. Soc. 1987, 109, 203-219. [CrossRef]

64. Butschke, B.; Schwarz, H. Thermal C-H Bond Activation of Benzene, Toluene, and Methane with Cationic $[\mathrm{M}(\mathrm{X})(\mathrm{bipy})]+(\mathrm{M}=$ $\mathrm{Ni}, \mathrm{Pd}, \mathrm{Pt} ; \mathrm{X}=\mathrm{CH} 3, \mathrm{Cl}$; bipy = 2,2'-bipyridine): A Mechanistic Study. Organometallics 2011, 30, 1588-1598. [CrossRef]

65. Henrici-olivé, G.; Olivé, S. The Active Species in Homogeneous Ziegler-Natta Catalysts for the Polymerization of Ethylene. Angew. Chem. Int. Ed. Engl. 1967, 6, 790-798. [CrossRef]

66. Machat, M.R.; Jandl, C.; Rieger, B. Titanocenes in Olefin Polymerization: Sustainable Catalyst System or an Extinct Species? Organometallics 2017, 36, 1408-1418. [CrossRef]

67. Machat, M.R.; Fischer, A.; Schmitz, D.; Vöst, M.; Drees, M.; Jandl, C.; Pöthig, A.; Casati, N.P.M.; Scherer, W.; Rieger, B. Behind the Scenes of Group 4 Metallocene Catalysis: Examination of the Metal-Carbon Bond. Organometallics 2018, 37, 2690-2705. [CrossRef]

68. Flisak, Z. Thermodynamics of Titanium and Vanadium Reduction in Non-Aqueous Environment Calculated at Various Levels of Theory. J. Phys. Chem. A 2012, 116, 1464-1468. [CrossRef] [PubMed]

69. Simoes, J.A.M.; Beauchamp, J.L. Transition metal-hydrogen and metal-carbon bond strengths: The keys to catalysis. Chem. Rev. 1990, 90, 629-688. [CrossRef]

70. Reints, W.; Pratt, D.A.; Korth, H.-G.; Mulder, P. O-O Bond Dissociation Enthalpy in Di(trifluoromethyl) Peroxide (CF3OOCF3) as Determined by Very Low Pressure Pyrolysis. Density Functional Theory Computations on O-O and O-H Bonds in (Fluorinated) Derivatives. J. Phys. Chem. A 2000, 104, 10713-10720. [CrossRef]

71. Fong, A.; Peters, B.; Scott, S.L. One-Electron-Redox Activation of the Reduced Phillips Polymerization Catalyst, via Alkylchromium(IV) Homolysis: A Computational Assessment. ACS Catal. 2016, 6, 6073-6085. [CrossRef]

72. Falivene, L.; Credendino, R.; Poater, A.; Petta, A.; Serra, L.; Oliva, R.; Scarano, V.; Cavallo, L. SambVca 2. A Web Tool for Analyzing Catalytic Pockets with Topographic Steric Maps. Organometallics 2016, 35, 2286-2293. [CrossRef]

73. Luo, Y.R. Comprehensive Handbook of Chemical Bond Energies; CRC Press: Boca Rayton, FL, USA, 2007.

74. Babushkin, D.E.; Panchenko, V.N.; Brintzinger, H.-H. Zirconium Allyl Complexes as Participants in Zirconocene-Catalyzed $\alpha$-Olefin Polymerizations. Angew. Chem. Int. Ed. 2014, 53, 9645-9649. [CrossRef] [PubMed]

75. Landis, C.R.; Christianson, M.D. Metallocene-catalyzed alkene polymerization and the observation of Zr-allyls. Proc. Natl. Acad. Sci. USA 2006, 103, 15349-15354. [CrossRef] [PubMed]

76. Sauriol, F.; Wong, E.; Leung, A.M.H.; Donaghue, I.E.; Baird, M.C.; Wondimagegn, T.; Ziegler, T. Structures and Properties of Nonchelated, d0 Alkyl Alkene Complexes of the Type [Cp2ZrMe(alkene)]+: Elusive Intermediates during Ziegler-Natta Polymerizations of Alkenes. Angew. Chem. Int. Ed. 2009, 48, 3342-3345. [CrossRef] [PubMed]

77. Moscardi, G.; Resconi, L.; Cavallo, L. Propene Polymerization with the Isospecific, Highly Regioselective rac-Me2C(3-t-Bu-1Ind)2ZrCl2/MAO Catalyst. 2. Combined DFT/MM Analysis of Chain Propagation and Chain Release Reactions. Organometallics 2001, 20, 1918-1931. [CrossRef]

78. Vatamanu, M. Observation of zirconium allyl species formed during zirconocene-catalyzed propene polymerization and mechanistic insights. J. Catal. 2015, 323, 112-120. [CrossRef]

79. Liu, B.; Wang, L.; Wu, C.; Cui, D. Sequence-controlled ethylene/styrene copolymerization catalyzed by scandium complexes. Polym. Chem. 2019, 10, 235-243. [CrossRef]

80. Dong, S.; Ou, Y.; Zhang, G. Preparations and Applications of the Brominated Polystyrenes with Low Molecular Weight. J. Funct. Polym. 1997, 10, 87-89.

81. Liu, D.T.; Yao, C.G.; Wang, R.; Wang, M.Y.; Wang, Z.C.; Wu, C.J.; Lin, F.; Li, S.H.; Wan, X.H.; Cui, D.M. Highly Isoselective Coordination Polymerization of ortho-Methoxystyrene with $\beta$-Diketiminato Rare-Earth-Metal Precursors. Angew. Chem. Int. Ed. 2015, 54, 5205-5209. [CrossRef]

82. Lenton, T.N.; Bercaw, J.E.; Panchenko, V.N.; Zakharov, V.A.; Babushkin, D.E.; Soshnikov, I.E.; Talsi, E.P.; Brintzinger, H.H. Formation of Trivalent Zirconocene Complexes from ansa-Zirconocene-Based Olefin-Polymerization Precatalysts: An EPR- and NMR-Spectroscopic Study. J. Am. Chem. Soc. 2013, 135, 10710-10719. [CrossRef]

83. Yamamoto, A.; Nishiura, M.; Yang, Y.; Hou, Z. Cationic Scandium Anisyl Species in Styrene Polymerization Using Anisole and N,N-Dimethyl-o-toluidine as Chain-Transfer Agents. Organometallics 2017, 36, 4635-4642. [CrossRef]

84. Teator, A.J.; Lastovickova, D.N.; Bielawski, C.W. Switchable Polymerization Catalysts. Chem. Rev. 2016, 116, 1969-1992. [CrossRef]

85. Grassi, A.; Zambelli, A.; Laschi, F. Reductive Decomposition of Cationic Half-Titanocene(IV) Complexes, Precursors of the Active Species in Syndiospecific Styrene Polymerization. Organometallics 1996, 15, 480-482. [CrossRef]

86. Nomura, K.; Izawa, I.; Yi, J.; Nakatani, N.; Aoki, H.; Harakawa, H.; Ina, T.; Mitsudome, T.; Tomotsu, N.; Yamazoe, S. Solution XAS Analysis for Exploring Active Species in Syndiospecific Styrene Polymerization and 1-Hexene Polymerization Using Half-Titanocene-MAO Catalysts: Significant Changes in the Oxidation State in the Presence of Styrene. Organometallics 2019. [CrossRef]

87. Bouyahyi, M.; Turki, Y.; Tanwar, A.; Jasinska-Walc, L.; Duchateau, R. Randomly Functionalized Polyethylenes: In Quest of Avoiding Catalyst Deactivation. ACS Catal. 2019, 9, 7779-7790. [CrossRef]

88. Poli, R. 3.11-Organometallic-Mediated Radical Polymerization. In Polymer Science: A Comprehensive Reference; Matyjaszewski, K., Möller, M., Eds.; Elsevier: Amsterdam, The Netherlands, 2012; pp. 351-375. [CrossRef] 
89. Allan, L.E.N.; Perry, M.R.; Shaver, M.P. Organometallic mediated radical polymerization. Prog. Polym. Sci. 2012, 37, 127-156. [CrossRef]

90. Asandei, A.D.; Moran, I.W. TiCp2Cl-Catalyzed Living Radical Polymerization of Styrene Initiated by Oxirane Radical Ring Opening. J. Am. Chem. Soc. 2004, 126, 15932-15933. [CrossRef]

91. Asandei, A.D.; Moran, I.W. The ligand effect in Ti-mediated living radical styrene polymerizations initiated by epoxide radical ring opening. 2. Scorpionate and half-sandwich LTiCl3 complexes. J. Polym. Sci. Part A Polym. Chem. 2005, 43, 6039-6047. [CrossRef]

92. Asandei, A.D.; Saha, G. Cp2TiCl-Catalyzed Epoxide Radical Ring Opening: A New Initiating Methodology for Graft Copolymer Synthesis. Macromolecules 2006, 39, 8999-9009. [CrossRef]

93. Stadler, S.M.; Göttker-Schnetmann, I.; Mecking, S. Incorporation of Radicals during Ni(II)-Catalyzed Ethylene Insertion Polymerization. ACS Catal. 2019, 9, 2760-2767. [CrossRef]

94. Stadler, S.M.; Göttker-Schnetmann, I.; Fuchs, A.S.; Fischer, S.R.R.; Mecking, S. Catalytic Chain Transfer Polymerization to Functional Reactive End Groups for Controlled Free Radical Growth. Macromolecules 2020, 53, 2362-2368. [CrossRef]

95. Ölscher, F.; Göttker-Schnetmann, I.; Monteil, V.; Mecking, S. Role of Radical Species in Salicylaldiminato Ni(II) Mediated Polymer Chain Growth: A Case Study for the Migratory Insertion Polymerization of Ethylene in the Presence of Methyl Methacrylate. J. Am. Chem. Soc. 2015, 137, 14819-14828. [CrossRef] [PubMed]

96. Keyes, A.; Basbug Alhan, H.E.; Ordonez, E.; Ha, U.; Beezer, D.B.; Dau, H.; Liu, Y.-S.; Tsogtgerel, E.; Jones, G.R.; Harth, E. Olefins and Vinyl Polar Monomers: Bridging the Gap for Next Generation Materials. Angew. Chem. Int. Ed. 2019, 58, 12370-12391. [CrossRef] [PubMed]

97. Dau, H.; Keyes, A.; Basbug Alhan, H.E.; Ordonez, E.; Tsogtgerel, E.; Gies, A.P.; Auyeung, E.; Zhou, Z.; Maity, A.; Das, A.; et al. Dual Polymerization Pathway for Polyolefin-Polar Block Copolymer Synthesis via MILRad: Mechanism and Scope. J. Am. Chem. Soc. 2020, 142, 21469-21483. [CrossRef] [PubMed]

98. Manßen, M.; Schafer, L.L. Titanium catalysis for the synthesis of fine chemicals-Development and trends. Chem. Soc. Rev. 2020, 49, 6947-6994. [CrossRef] [PubMed]

99. Ma, K.; Piers, W.E.; Gao, Y.; Parvez, M. Isolation and Characterization of a Monomeric Cationic Titanium Hydride. J. Am. Chem. Soc. 2004, 126, 5668-5669. [CrossRef] [PubMed]

100. Ma, K.; Piers, W.E.; Parvez, M. Competitive ArC $-\mathrm{H}$ and $\mathrm{ArC}-\mathrm{X}(\mathrm{X}=\mathrm{Cl}, \mathrm{Br})$ Activation in Halobenzenes at Cationic Titanium Centers. J. Am. Chem. Soc. 2006, 128, 3303-3312. [CrossRef]

101. Sato, F.; Urabe, H.; Okamoto, S. Synthesis of Organotitanium Complexes from Alkenes and Alkynes and Their Synthetic Applications. Chem. Rev. 2000, 100, 2835-2886. [CrossRef]

102. Carpenetti, D.W. Models of intermediates in metallocene-catalyzed alkene polymerizations: Observation of a d0 cationic titanium-alkyl-alkene complex and decomposition by $\beta$-allyl elimination. Inorg. Chem. Commun. 2003, 6, 1287-1290. [CrossRef]

103. Sauriol, F.; Sonnenberg, J.F.; Chadder, S.J.; Dunlop-Brière, A.F.; Baird, M.C.; Budzelaar, P.H.M. Remarkable Reactions and Intermediates in Titanocene(IV) Chemistry: Migratory Insertion Reactions of 2,2-Disubstituted-1-alkenes, Intramolecular 1,5- $\sigma$ Bond Metathesis via $\varepsilon$-Agostic Interactions, and a Rare Example of a $\beta$-Agostic Alkyltitanocene Complex. J. Am. Chem. Soc. 2010, 132, 13357-13370. [CrossRef]

104. Li, F.; Lin, S.; Chen, Y.; Shi, C.; Yan, H.; Li, C.; Wu, C.; Lin, L.; Duan, C.; Shi, L. Photocatalytic Generation of $\pi$-allyltitanium Complexes via Radical Intermediates. Angew. Chem. Int. Ed. 2020. [CrossRef]

105. van der Heijden, H.; Hessen, B.; Orpen, A.G. A Zwitterionic Zirconocene Alkyl Complex as a Single-Component $\alpha$-Olefin Dimerization Catalyst. J. Am. Chem. Soc. 1998, 120, 1112-1113. [CrossRef]

106. Horton, A.D. Direct Observation of $\beta$-Methyl Elimination in Cationic Neopentyl Complexes: Ligand Effects on the Reversible Elimination of Isobutene. Organometallics 1996, 15, 2675-2677. [CrossRef]

107. Vatamanu, M. Synthesis, Structures, and Dynamic Features of d0 Zirconocene-Allyl Complexes. Organometallics 2014, 33, 3683-3694. [CrossRef] 